\title{
Down-regulation of promoter methylation level of CD4 gene after MDV infection in MD-susceptible chicken line
}

\author{
Juan Luo ${ }^{1 \dagger}$, Ying $\mathrm{Yu}^{1,3+}$, Huanmin Zhang ${ }^{2}$, Fei Tian', Shuang Chang ${ }^{2}$, Hans H Cheng ${ }^{2}$, Jiuzhou Song ${ }^{* *}$ \\ From International Symposium on Animal Genomics for Animal Health (AGAH 2010) \\ Paris, France. 31 May - 2 June 2010
}

\begin{abstract}
Background: Marek's disease virus (MDV) is an oncovirus that induces lymphoid tumors in susceptible chickens, and may affect the epigenetic stability of the CD4 gene. The purpose of this study was to find the effect of MDV infection on DNA methylation status of the CD4 gene differed between MD-resistant $\left(L \sigma_{3}\right)$ and - susceptible $\left(L 7_{2}\right)$ chicken lines.

Methods: Chickens from each line were divided into two groups with one group infected by MDV and the other group as uninfected controls. Then, promoter DNA methylation levels of the CD4 gene were measured by Pyrosequencing; and gene expression analysis was performed by quantitative PCR.

Results: Promoter methylation of the CD4 gene was found to be down-regulated in $L 7_{2}$ chickens only after MDV infection. The methylation down-regulation of the CD4 promoter is negatively correlated with up-regulation of CD4 gene expression in the $L 7_{2}$ spleen at 21 dpi.
\end{abstract}

Conclusions: The methylation fluctuation and mRNA expression change of CD4 gene induced by MDV infection suggested a unique epigenetic mechanism existed in MD-susceptible chickens.

\section{Background}

CD4 encodes a glycoprotein, located on the surface of $\mathrm{T}$ helper (Th) cells and regulatory $\mathrm{T}$ cells. Through interaction with MHC class II molecules, CD4 directs the linage development of Th cells in immune organs and activates the $\mathrm{CD} 4^{+} \mathrm{T}$ cell maturation process [1]. Thus, the transcriptional level of $C D 4$ is directly related to $\mathrm{T}$ cell development [2]. In mice, CD4 transcription is controlled by several cis-acting elements including enhancers, silencers and DNA methylation [3,4]. However, the epigenetic regulation of $C D 4$ gene in chicken and its relationship with any virus infection are still unclear....

Marek's disease (MD), a T cell lymphoma of chickens caused by the Marek's disease virus (MDV), is

\footnotetext{
* Correspondence: songj88@umd.edu

+ Contributed equally

'Animal \& Avian Sciences Department, University of Maryland, College Park, Maryland, 20740, USA

Full list of author information is available at the end of the article
}

characterized by mononuclear cell-infiltration in various organs including peripheral nerves, skin, muscle, and visceral organs [5], and is a worldwide problem for the poultry industry. A complex MDV life cycle was found in susceptible chickens during MD progression, which includes an early cytolytic phase (2-7 days post infection, dpi), latent phase (7-10 dpi), late cytolytic phase (from $18 \mathrm{dpi}$ ) and transformation phase $(28 \mathrm{dpi}$ and onwards) [6].

Epigenetics is the study of alterations that result in inherited changes in phenotypes despite the lack of DNA sequence polymorphisms and include DNA methylation, histone modification and chromatin remodeling [7]. It is described as the interaction between genes and environmental factors. Aberrant $\mathrm{CpG}$ methylation levels of the gene promoter region contribute to oncogenesis [8]. Viruses are one of the environmental agents that can cause alterations of DNA methylation level in host genes [9]. 
The focus of this study was to better understand the expression control of $C D 4$ by ascertaining the epigenetic status in the CD4 promoter and the CD4 expression in relation to MDV infection. Two inbred chicken lines, MD-resistant or -susceptible with the same MHC (major histocompatibility complex) haplotypes, from Avian Disease and Oncology laboratory (ADOL) were used [5]. We, therefore, measured the promoter methylation and transcription of the CD4 gene before and after MDV infection of both lines. We found methylation alterations in the $C D 4$ promoter region after MDV infection differ between these two lines.

\section{Methods}

Animals, virus infection experiments and sample collection

USDA, Avian Disease and Oncology Laboratory (ADOL) chicken lines $6\left(\mathrm{~L}_{3}{ }_{3}\right.$ and lines $7\left(\mathrm{~L}_{2}{ }^{)}\right.$chickens, which are MD-resistant and MD-susceptible, respectively, were obtained. For each line, the chickens were divided into two groups with 30 chickens infected by MDV and 30 uninfected controls. A very virulent plus strain of MDV (648A passage 40, VV+) was injected intra-abdominally on the fifth day after hatching with 500 plaque-forming units (PFU). Spleen samples were collected at $5 \mathrm{dpi}, 10 \mathrm{dpi}$ and $21 \mathrm{dpi}$, put in RNAlater (Qiagen, USA) immediately, and then stored at $-80^{\circ} \mathrm{C}$. All procedures followed the standard animal ethics and user guidelines.

\section{DNA extraction, bisulfite treatment and pyrosequencing} DNA was extracted from 20-30 mg spleen by NucleoSpin $^{\circledR}$ Tissue Kits (Macherey-Nagel, Germany). 500 ng DNA was treated with sodium bisulfite and purified by EZ DNA Methylation-Gold Kit ${ }^{\mathrm{TM}}$ (ZYMO Research, USA). Primers for pyrosequencing were designed by PSQ Assay Design software (Biotage, Swedan) (Table 1). For cost reduction, a universal primer (5'-GGGACACCGCTGATCGTTTA-3') was used in the PCR assays [10]. DNA methylation level analysis was performed with Pyro Q-CpG system (PyroMark ID, Biotage, Sweden) as previously described $[10,11]$.

\section{RNA extraction and quantitative real-time RT-PCR}

RNA from 30-50mg spleen was extracted using the RNAeasy Mini Kit (Qiagen, USA). Reverse transcription was carried out in $20 \mu \mathrm{l}$ with $1 \mu \mathrm{g}$ of total RNA by using SuperScript ${ }^{\mathrm{TM}}$ III Reverse Transcriptase (Invitrogen, USA) and oligo (dT) $)_{12-18}$ primers (Invitrogen, USA). Primers (Table 1) for quantitative real-time RTPCR were designed by Primer3 online primer designer system (http://frodo.wi.mit.edu/). qPCR was performed on the iCycler iQ PCR system (Bio-Rad, USA) in a final volume of $20 \mu \mathrm{l}$ using QuantiTect SYBR Green PCR Kit (Qiagen, USA) with the following procedure: denatured at $95^{\circ} \mathrm{C}$ for $15 \mathrm{~min}$, followed by 40 cycles at $95{ }^{\circ} \mathrm{C}$ for 30 s, $60{ }^{\circ} \mathrm{C}$ for $30 \mathrm{~s}, 72{ }^{\circ} \mathrm{C}$ for $30 \mathrm{~s}$, then extended at $72{ }^{\circ} \mathrm{C}$ for $10 \mathrm{~min}$. Each reaction was replicated twice. The housekeeping gene GAPDH (glyceraldehyde-3-phosphate dehydrogenase) was used to normalize the assays.

\section{Statistical analysis}

Promoter methylation levels and gene expression before and after MDV infection were compared by Student's $t$ test. An exact $F$ test was performed to distinguish different methylation patterns [10]. Correlation between CD4 DNA methylation and expression was tested by Pearson's correlation coefficient.

\section{Results}

CD4 promoter methylation analysis before and after MDV infection

To determine the promoter methylation level of the CD4 gene, a DNA sequence containing the CpG islands from the CD4 gene promoter region (sequence shown in Table 1) was downloaded from UCSC (http://genome.ucsc.edu) and the methylation level was determined by pyrosequencing. The CpGs in the promoter of CD4 exhibits a high (>70\%) methylation level in both $\mathrm{L}_{3}$ and $\mathrm{L}_{2}$ chickens before MDV infection. During MD progression, no significant methylation changes of $C D 4$ promoter were detected in $\mathrm{L}_{3}$ chickens at 5,10 and $21 \mathrm{dpi}$ or in $\mathrm{L} 7_{2}$ chickens at 5 and $10 \mathrm{dpi}(P>0.05$, Figure 1 , and Figure $1 \mathrm{~A}$ and $1 \mathrm{~B})$; however, the significant down-regulation of CD4 promoter methylation level was observed at $21 \mathrm{dpi}$ in $\mathrm{L}_{2}$ chickens

Table 1 Primers used in Pyrosequencing and quantitative PCR

\begin{tabular}{|c|c|c|c|}
\hline Genes & Primers & Sequence & Purpose \\
\hline CD4 & $\begin{array}{l}\mathrm{F} \\
\mathrm{R} \\
\text { Sequencing } \\
\text { Assay }\end{array}$ & $\begin{array}{l}\text { 5'- TTGAGATTATAYGTATITGGAAGA -3' } \\
\text { 5'- GGGACACCGCTGATCGTITA ACCTITATATCTCCTCCTCTCCA -3' } \\
\text { 5'- AGTATITATTGAGAGAAGTT -3' } \\
\text { 5'- YGTAGATTGTAGTAGAGTITGGATYG } \\
\text { GTAGTAAGATYGTGTTGAYGTIT -3' }\end{array}$ & Pyrosequencing \\
\hline GAPDH & $\begin{array}{l}F \\
R\end{array}$ & $\begin{array}{l}\text { 5'-GAGGGTAGTGAAGGCTGCTG-3' } \\
\text { 5'-ACCAGGAAACAAGCTTGACG-3' }\end{array}$ & quantitative $P C R$ \\
\hline CD4 & $\begin{array}{l}F \\
R\end{array}$ & $\begin{array}{l}\text { 5'- TGTCAACGCCGGATGTATAA-3' } \\
\text { 5'- CTTGTCCATTGGCTCCTCTC-3' }\end{array}$ & quantitative $P C R$ \\
\hline
\end{tabular}

$\mathrm{Y}$ stands for $\mathrm{C} / \mathrm{T}$. Bold $\mathrm{Y}$ in the assay sequence is the $\mathrm{CpG}$ sites analyzed. 


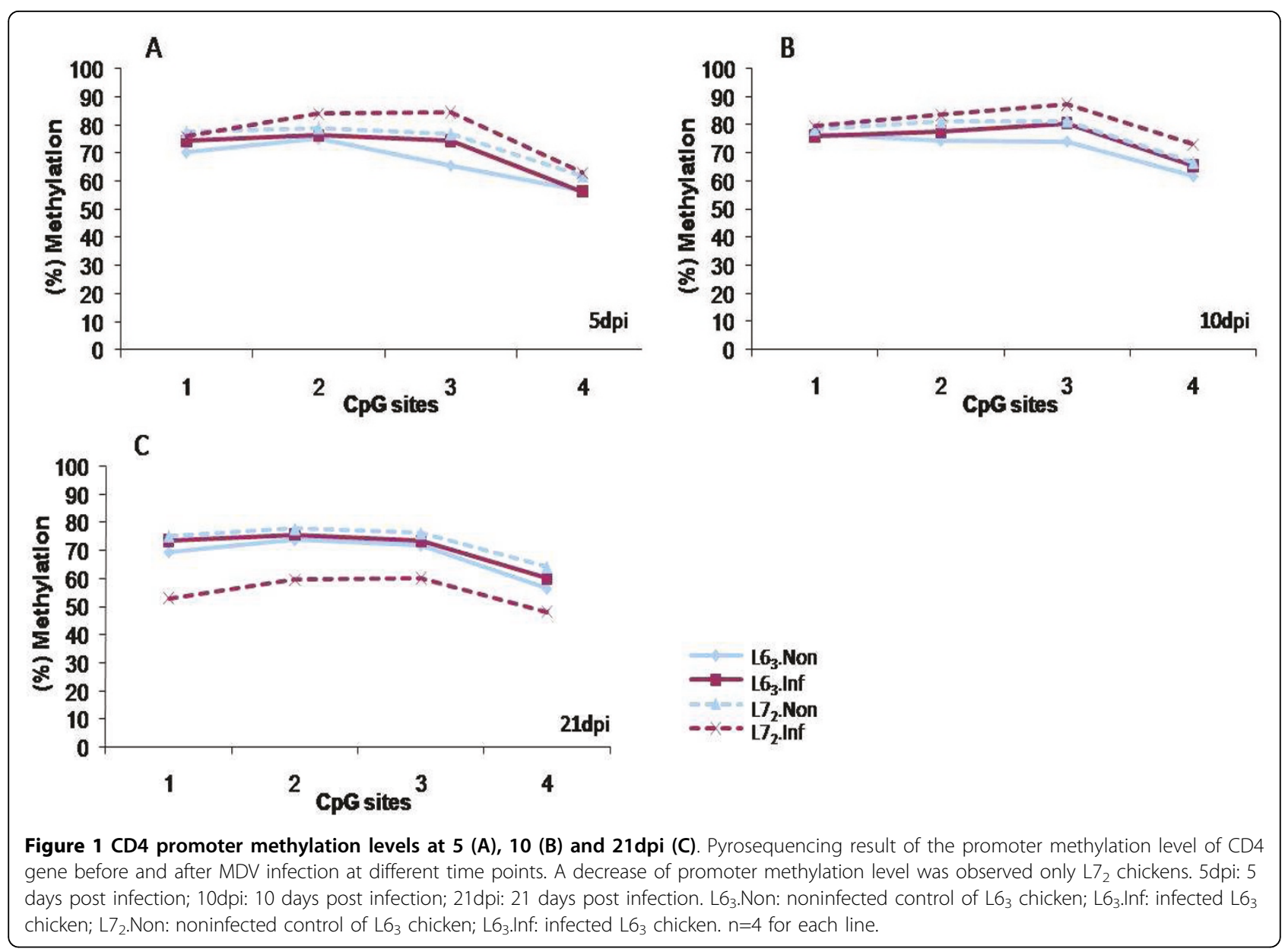

$(P<0.05$, Figure $1 C)$. The result from the exact $F$ test revealed that the $C D 4$ promoter methylation pattern in $\mathrm{L}_{2}$ infected samples at $21 \mathrm{dpi}$ was significantly different from any other groups (Figure 2).

\section{CD4 gene expression at $21 \mathrm{dpi}$}

To ascertain if the CD4 gene transcription level is influenced by its promoter methylation changes at $21 \mathrm{dpi}$, we conducted quantitative PCR. We found a significantly higher expression of $C D 4$ gene in $\mathrm{L}_{2}$ infected samples compared with noninfected control samples $(P<0.05)$ (Figure 3$)$, whereas no significant up or downregulation of $C D 4$ expression was detected in $\mathrm{L}_{3}$ chickens after MDV infection $(P>0.05)$. Hereinafter, further correlation analysis showed that methylation level of all the detected CpG sites existed a negatively relationship with $C D 4$ gene expression in $\mathrm{L}_{2}$ chicken at 21dpi (Figure 4).

\section{Discussion}

The $C D 4$ gene and its regulatory sequences are conserved [12]. In human and mouse, multiple protein or transcription factor binding sites, including the Myb binding site, Elf- 1 binding site, and Ikaros binding site, were found in the promoter region of $C D 4$, which is involved in the on/off switching of CD4 gene expression [4]. These regulatory sites were also found in the chicken $C D 4$ promoter with potential functions in its expression [12]. It is well known that epigenetic factors such as DNA methylation and histone modifications play important roles in transcriptional regulation in mammals [7]. For example. the methylation change in at least one CpG site of $C D 4$ gene in mouse is related to $\mathrm{CD} 4^{+} \mathrm{T}$ cell differentiation [3]. In this study, we thus examined the methylation status in the promoter region of $C D 4$ gene in chickens related to MDV infection.

MDV is an oncovirus using CD4+ T cell as a target for latent infection and transformation, which may have interactions with the CD4 gene at the epigenetic level [13]. In our previously study, two mutations (CG $\rightarrow$ TG) were identified in the DNMT3b gene between L63 and L72 chickens [10], which implied that the DNA methylation machinery may be different in the two lines in response to MDV infection. In this study, the 


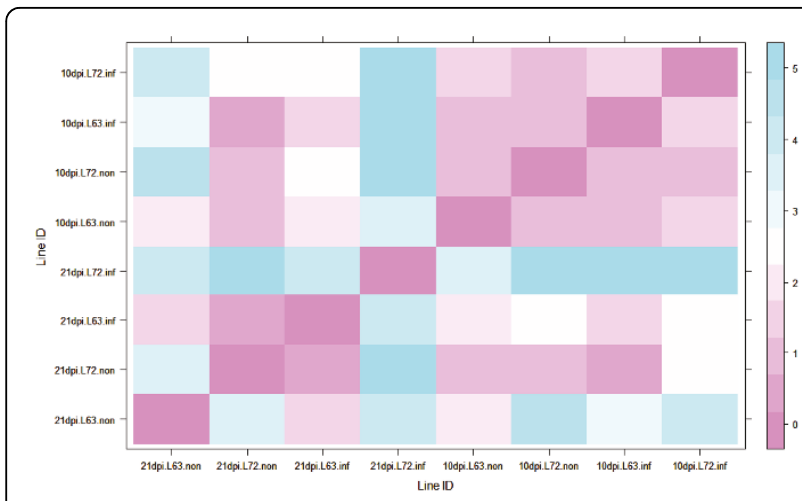

Figure 2 Exact $\mathrm{F}$ test for DNA methylation patterns of CD4. The methylation level of each of the $\mathrm{CpG}$ site in the promoter region of CD4 gene was used to do an exact $F$ test. $P$ values matrix among $\mathrm{LG}_{3}$ and $\mathrm{L} 7_{2}$ at 5, 10 and $21 \mathrm{dpi}$. Color bar shows the significance level $\left(P\right.$ values with $-\log _{10}(P)$. e.g., $-\log _{10}(0.05)=1.3$; $\left.\log 10(0.01)=2\right)$.

methylation levels on the promoter region of the CD4 gene were fluctuated over different time points of MDV infection in MD-susceptible chickens, especially during the late cytolytic phase. The quantitative PCR results confirmed that CD4 expression in L72 chicken during the late stages of MDV infection was upregulated while the CD4 promoter methylation was down-regulation. Since the expression of CD4 is essential for CD4+ T cell development and activation, it may suggest that there are different epigenetic machineries of activation of CD4 $+\mathrm{T}$ cells by MDV infection through regulation of CD4 methylation levels between MD-resistant and susceptible chicken lines. From previous studies, it was found that the number of infected $\mathrm{CD} 4+\mathrm{T}$ cells were similar

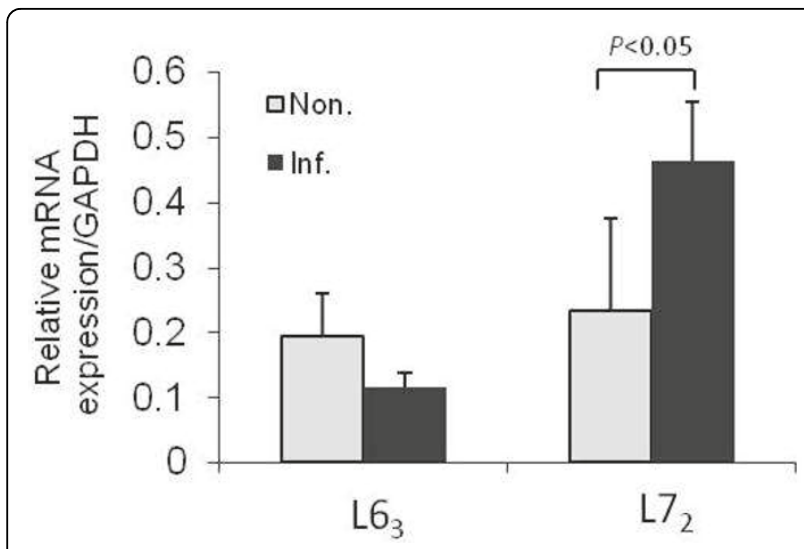

Figure 3 Relative mRNA expression of CD4 gene at $21 \mathrm{dpi}$. Realtime quantitative PCR was used to detect the mRNA expression level of CD4 gene in different chicken lines with or without MDV infection at $21 \mathrm{dpi}$. The relative expression level of CD4 gene was normalized to a house keeping gene GAPDH. Non:: noninfected control samples; Inf:: infected samples. $n=4$ for each line and treatment.

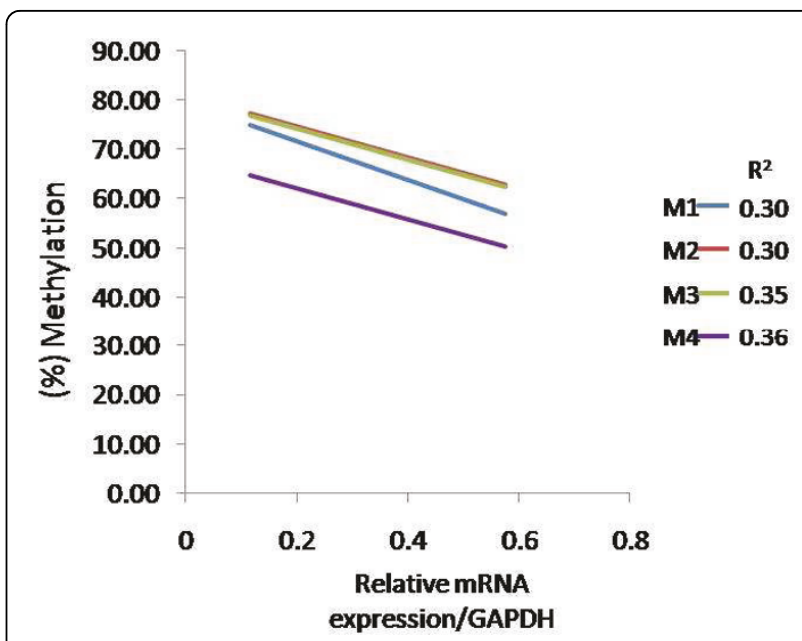

Figure 4 Correlation between CD4 promoter methylation and relative gene expression in $\mathbf{L 7 2}$ spleen at $\mathbf{2 1 d p i . ~ C o r r e l a t i o n ~}$ analysis of the relationship between methylation and CD4 gene mRNA expression level. $R$ represents for the correlation coefficient. M1: CpG site 1; M2: CpG site 2; M3: CpG site3; M4: CpG site 4. $n=4$ for each line and treatment.

during the early phase (cytolytic phase) of MDV infection between MD-resistant and -susceptible chicken lines, but was increased during cytolytic phase in MDsusceptible chicken line and decreased in MD-resistant chicken line [14]. Additionally, in MD-resistant chicken line, CD4+ T cell is latently infected, but cannot be transformed, whereas in MD-susceptible chicken lines the infected $\mathrm{CD} 4+\mathrm{T}$ cell can be transformed after the latent phase $[5,15]$. Taken together, the methylation change of CD4 gene gives us an important clue that epigenetic alteration could associate with MD etiology. Therefore, future efforts will disclose the epigenetic landscapes, including genome-wide DNA methyltion and histone modifications, in immune organs and specific cell types, such as the CD4+ T cell, which will supply rich information to explore the epigenetic machinery related to chemical and physiological mechanisms of MD resistance or susceptibility.

\section{Conclusions}

In conclusion, the methylation fluctuation and mRNA expression of $C D 4$ gene induced by MDV infection suggested a unique epigenetic mechanism existed in MDsusceptible chickens.

\section{Acknowledgements}

The study was grant-supported by NIFA 2008-35204-04660

This article has been published as part of BMC Proceedings Volume 5 Supplement 4, 2011: Proceedings of the International Symposium on Animal Genomics for Animal Health (AGAH 2010). The full contents of the supplement are available online at http://www.biomedcentral.com/1753$6561 / 5$ ? issue $=\$ 4$ 


\section{Author details}

'Animal \& Avian Sciences Department, University of Maryland, College Park, Maryland, 20740, USA. ${ }^{2}$ USDA, ARS, Avian Disease and Oncology Laboratory, East Lansing, MI 48823, USA. ${ }^{3}$ College of Animal Sciences, China Agricultural University, Haidian, Beijing, 100193, P.R. China.

\section{Authors' contributions}

$J \mathrm{~L}$ performed the experiments and prepare the manuscript. YY and FT performed the experiments. $\mathrm{HMZ}$ and $\mathrm{SC}$ designed and performed the viral challenge experiment. JZS designed and wrote the paper.

\section{Competing interests}

The authors declare that they have no competing interests.

Published: 3 June 2011

\section{References}

1. Huang Z, Xie H, loannidis V, Held W, Clevers H, Sadim MS, Sun Z: Transcriptional regulation of CD4 gene expression by $\mathrm{T}$ cell factor-1/ beta-catenin pathway. J Immunol 2006, 176(8):4880-4887.

2. Paillard F, Sterkers G, Vaquero C: Transcriptional and post-transcriptional regulation of TCR, CD4 and CD8 gene expression during activation of normal human T lymphocytes. Embo J 1990, 9(6):1867-1872.

3. Tutt Landolfi MM, Scollay R, Parnes JR: Specific demethylation of the CD4 gene during CD4 T lymphocyte differentiation. Mol Immunol 1997, 34(1):53-61.

4. Ellmeier W, Sawada S, Littman DR: The regulation of CD4 and CD8 coreceptor gene expression during T cell development. Annu Rev Immunol 1999, 17:523-524.

5. Davison F, Nair V: Marek's Disease: An Evolving Problem. Oxford: Elsevier Academic Press; 2004.

6. Calnek BW: Pathogenesis of Marek's disease virus infection. Curr Top Microbiol Immunol 2001, 255:25-55.

7. Allis CD, Jenuwein T, Reinberg D, Caparros M-L: Epigenetics. Cold Spring Harbor Laboratory Press; 2006.

8. Herman JG, Baylin SB: Gene silencing in cancer in association with promoter hypermethylation. N Engl J Med 2003, 349(21):2042-2054.

9. Amara K, Trimeche M, Ziadi S, Laatiri A, Hachana M, Sriha B, Mokni M, Korbi S: Presence of simian virus 40 DNA sequences in diffuse large Bcell lymphomas in Tunisia correlates with aberrant promoter hypermethylation of multiple tumor suppressor genes. Int J Cancer 2007, 121(12):2693-2702.

10. Yu Y, Zhang $H$, Tian F, Zhang W, Fang $H$, Song J: An integrated epigenetic and genetic analysis of DNA methyltransferase genes (DNMTs) in tumor resistant and susceptible chicken lines. PLOS ONE 2008, 3(7):e2672.

11. Colella S, Shen L, Baggerly KA, Issa JP, Krahe R: Sensitive and quantitative universal Pyrosequencing methylation analysis of $\mathrm{CpG}$ sites. Biotechniques 2003, 35(1):146-150.

12. Koskinen R, Salomonsen J, Tregaskes CA, Young JR, Goodchild M, Bumstead N, Vainio O: The chicken CD4 gene has remained conserved in evolution. Immunogenetics 2002, 54(7):520-525.

13. Rouse BT, Wells RJ, Warner NL: Proportion of T and B lymphocytes in lesions of Marek's disease: theoretical implications for pathogenesis. J Immunol 1973, 110(2):534-539.

14. Burgess SC, Basaran BH, Davison TF: Resistance to Marek's disease herpesvirus-induced lymphoma is multiphasic and dependent on host genotype. Vet Pathol 2001, 38(2):129-142.

15. Burgess SC, Davison TF: Identification of the neoplastically transformed cells in Marek's disease herpesvirus-induced lymphomas: recognition by the monoclonal antibody AV37. J Virol 2002, 76(14):7276-7292.

doi:10.1186/1753-6561-5-S4-S7

Cite this article as: Luo et al.: Down-regulation of promoter methylation level of CD4 gene after MDV infection in MD-susceptible chicken line. BMC Proceedings 2011 5(Suppl 4):S7. 